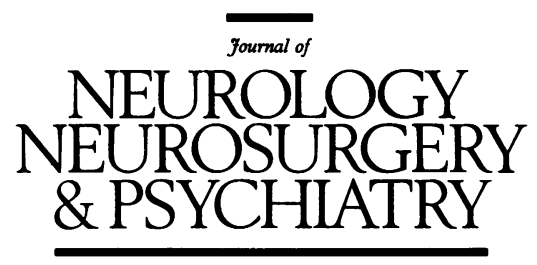

Editorial

\title{
Tropical spastic paraparesis and human T-cell lymphotropic virus type 1
}

Retroviruses are characterised by the presence of reverse transcriptase, an enzyme that enables the viral genetic RNA to be transcribed into a DNA code which can then be inserted into the host's genome. ${ }^{1}$ There are three families of retroviruses two of which-the oncovirinae and lentivirinae-are pathogenic. As these names suggest some of the viruses are associated with tumours, especially leukaemias and lymphomas, and cause diseases of prolonged incubation. Of particular interest to the neurologist is the fact that a given retrovirus can be associated with two distinct pathological processes in a host species, one of which frequently involves the nervous system. For example the viruses causing murine leukaemia, ovine pneumonitis, caprine arthritis, equine infectious anaemia and simian immune deficiency are all associated with meningoencephalitides of various types. These disorders, with the exception of simian immune deficiency syndrome, have been well recognised by veterinary clinicians for decades and ovine visna/maedi (an encephalitis and pneumonitis) was one of the diseases that originally led Sigurdsson to formulate his concept of slow infections. ${ }^{2}$ At the beginning of this decade the attention of medical clinicians was drawn to retroviruses by the work of Gallo et al who showed that adult T-cell leukaemia (ATL) was associated with a retrovirus-human $\mathrm{T}$-cell lymphotropic virus type 1 (HTLV 1). ${ }^{3}$ Subsequently these workers and others have isolated a number of retroviruses pathogenic in humans viz: HTLV 2 associated with hairy cell leukaemia and the human immune deficiency viruses HIV 1 and 2. It should come as no surprise that two of these retroviruses (HTLV 1 and HIV 1) have been associated with neurological disease.

In 1985 Gessain et al $^{4}$ demonstrated that patients from Martinique with tropical spastic paraparesis (TSP) had antibodies to HTLV 1 in their serum, an observation that has been amply confirmed and extended; HTLV 1 antibodies are frequently found in patients with TSP throughout the Caribbean, in parts of the South American mainland notably Colombia and in European migrants from these areas. ${ }^{5}$ On the other side of the world in Japan, an area of high prevalence of ATL, a proportion of patients with progressive myelopathy of unknown cause were also shown to have antibodies to HTLV 1 . Osame et $a l^{6}$ called this condition HTLV 1 associated myelopathy (HAM). Subsequent studies have shown that patients with TSP and HAM have an essentially similar clinical and pathological condition that is identical to that seen in Jamaican neuropathy described by Montgomery and co-workers. ${ }^{7}$
The disease primarily affects adults aged $30-60$ years and has a female preponderance. ${ }^{8}$ It is characterised by an insidious onset of back and radicular pain followed by a slowly progressive paraparesis with sphincter involvement. Minor pyramidal signs are found in the upper limbs in some patients. The cranial nerves are usually spared clinically but visual and auditory evoked potential studies, especially in Afro-Caribbean subjects, are abnormal in about half. Magnetic resonance imaging (MRI) of the brain shows minor white matter and periventricular changes but these are rarely as marked as in patients with long standing multiple sclerosis (MS), although on occasion the MRI appearances are indistinguishable. The dorsal cord is usually atrophic and the cerebrospinal fluid (CSF) contains oligoclonal bands some of which recognise HTLV 1 antigens. Virus has been isolated from mononuclear cells in the blood and CSF of TSP patients and has been shown to be integrated into the host genome. ${ }^{9}$

In this issue of the Journal ${ }^{10}$ Kayembe et al describe the first definitive series of TSP from Africa. This report is of particular interest as it concerns a familial cluster of TSP cases within an ethnic minority and addresses two important points. The first concerns the transmission of HTLV 1. One might expect a disease associated with an infectious agent to occur in a non-random manner within a population and indeed this is the case with ATL caused by HTLV 1. Thus in South Japan, where the highest concentration of the disease is found, $13 \%$ of cases of ATL are familial. ${ }^{11}$ Although there have been estimates that a similar or even greater proportion of TSP cases are familial, and isolated examples of familial TSP have been published, ${ }^{12} 13$ Kayembe and colleagues are the first to obtain evidence of such clustering. They show that half the 21 families they studied contains another member with TSP. Further, in seven families it was the mother and her child who were affected while there was no case of both the father and child having the disease. This suggests that the transmission of HTLV 1 occurs from the mother to her offspring, an observation supported by studies of HTLV 1 antibodies in families with ATL in Japan ${ }^{14}$ and also by similar studies of TSP families in the United Kingdom (unpublished data). Although Kayembe et al have no data on the mode of transmission it does seem that in Japan, apart from the known risks of blood transfusion, breast milk is the source of infection in infants and semen the main cause of infection in adults. ${ }^{15}$

The second reason why this paper is important concerns 
genetic susceptibility to TSP. It is known that HTLV 1 is widespread in areas where TSP and ATL are endemic but that the vast majority of carriers are asymptomatic. From work with murine leukaemia virus there is evidence that both the host and viral genetic constitution can be important in determining whether a carrier develops leukaemia or myelopathy. ${ }^{16}$ In humans there is no good evidence that there is a specific neurogenic mutant of HTLV 1 causing $\mathrm{TSP}^{1718}$ but there is some, not very convincing, evidence from Japan to suggest that certain host HLA phenotypes are associated with TSP (HAM) while individuals with other phenotypes are susceptible to ATL. ${ }^{19}$ The paper by Kayembe and co-worker's addresses this problem. Their study area contained three tribes of which one accounted for only $10 \%$ of the total population, but $50 \%$ of the patients with TSP came from this group. The authors point out that since there is a significantly non-random distribution of TSP within these tribes but HTLV 1 infection is widespread these observations bear witness to genetic factors playing an important part in determining whether a patient develops TSP or remains asymptomatic. Further studies involving HLA typing are in progress to confirm or refute this hypothesis; the results are eagerly awaited.

The initial chance observation that TSP is associated with a retrovirus has probably been the most significant advance in neurology in the past five years. How such an infection leads to neurological damage is at present mysterious. Hopefully, further work will enable a clearer picture of the pathogenesis of TSP to emerge and perhaps lead to the discovery of novel retroviruses that cause some of the many diseases of obscure origin confronting the neurologist.

National Hospital,

Queen Square, London
1 Lin FH, Thormar H. Ribonucleic acid-dependent deoxyribonucleic acid polymerase in visna virus. $J$ Virol 1970;6:702.

2 Sigurdsson B. Rida, a chronic encephalitis of sheep, with general remarks on infections which develop slowly and some of their special characteristics. Brit Vet J 1954;110:341.

3 Poiesz BJ, Ruscetti FW, Gazdar AF, Bunn PA, Minna JD, Gallo RC. Detection and isolation of type $C$ retrovirus particles from fresh and cultured lymphocytes of a patient with cutaneous T-cell lymphoma. Proc Natl Acad Sci USA 1980;77:7415.

4 Gessain A, Barin F, Vernant JC, et al. Antibodies to human T-lymphotropic virus type 1 in patients with tropical spastic paraparesis. Lancet virus type $1985 ;$ ii:407.
19.

5 Dalgleish AG, Richardson J, Matutes E, et al. HTLV1 infection in tropical spastic paraparesis: lymphocyte culture and enhanced serological response. AIDS Research and Human Retroviruses 1988;4:475.

6 Osame M, Matsumoto M, Usuku K, et al.Chronic progressive myelopathy with elevated antibodies to human $\mathrm{T}$ lymphotropic virus type 1 and adult T-cell leukemia-like cells. Ann Neurol 1987;21:117.

7 Montgomery RD, Cruickshank EK, Robertson WB. McMenemey WH Clinical and pathological observations in Jamaican neuropathy: a report on 206 cases. Brain 1964;87:425.

8 Cruickshank JK, Rudge P, Dalgleish AG, et al. Tropical spastic paraparesis and human T cell lymphotropic virus type 1 in the United Kingdom. Brain 1989;112:1057.

9 Bhagavati S, Ehrlich G, Kula RW, et al. Detection of human T-cell lymphoma/leukemia virus type 1 DNA and antigen in spinal fluid and blood of patients with chronic progressive myelopathy. New Eng J Med 1988;318:1141.

10 Kayembe K, Goubau P, Desmyter J, Vlietinck R, Carton H. A cluster of HTLV 1 associated tropical spastic paraparesis in Equateur (Zaire): ethnic and familial distribution. J Neurol Neurosurg Psychiatry 1990;53:4

11 Kondo T, Nonaka $\mathrm{H}$, Miyamoto N, et al. Incidence of adult $T$-cell leukaemia-lymphoma and its familial clustering. Intl $J$ Cancer 1985;35:601.

12 Miyai I, Saida T, Fujita M, et al. Familial cases of HTLV 1 associated myelopathy. Ann Neurol 1987;22:601.

13 Mori M, Ban N, Kinoshita K. Familial occurrence of HTLV 1 associated myelopathy. Ann Neurol 1987;23:100.

14 Kajiyama W, Kashiwagi S, Ikematsu H, Hayashi J, Nomura H, Okochi K. Intrafamilial transmission of adult T-cell leukemia virus. J Infect Dis 1986;154:851.

15 Nakano S, Ando Y, Ichijo $M$, et al. Search for possible routes of vertical and horizontal transmission of adult T-cell leukemia virus. Gann 1984; horizontal 1044 .

16 Rassart E, Nelbach L, Jolicoeur P. Cas-Br-E murine leukemia virus: sequencing of the paralytogenic region of its genome and derivation of specific probes to study its origin and the structure of its recombinan genomes in leukemic tissues. JVirol 1986;60:910.

17 Bangham CRM, Daenke S, Phillips RE, Cruickshank JK, Bell JI. Enzymic amplification of exogenous retrovirus sequences from DNA of patients with tropical spastic paraparesis. $E M B O J 1988 ; 4179$.

18 Tsujimoto A, Teruuchi T, Imamura J, Shimotonno K, Miyoshi K, Miwa M. Nucleotide sequence analysis of a provirus derived from HTLV1 associated myelopathy (HAM). Mol Biol Med 1988;5:29.

19 Usuku K, Sonoda S, Osame M, et al. HLA haplotype-linked high immune responsiveness against HTLV1 associated myelopathy: comparison with responsiveness against HThl associated myelopathy: comparison with
adult T-cell leukemia/lymphoma. Ann Neurol 23( Suppl) 1988; 143 . 